University of Nebraska - Lincoln

DigitalCommons@University of Nebraska - Lincoln

$10-2009$

\title{
Satellite Estimation of Chlorophyll-a Concentration Using the Red and NIR Bands of MERIS-The Azov Sea Case Study
}

Wesley J. Moses

University of Nebraska-Lincoln, wmoses.unl@gmail.com

Anatoly A. Gitelson

University of Nebraska-Lincoln, agitelson2@unl.edu

Sergey Berdnikov

Southern Scientific Center of the Russian Academy of Sciences, Rostov-on-Don, berdnikov@mmbi.krinc.ru

Vasiliy Povazhnyy

Southern Scientific Center of the Russian Academy of Sciences, Rostov-on-Don, povazhnyi@mmbi.krinc.ru

Follow this and additional works at: https://digitalcommons.unl.edu/natrespapers

Part of the Natural Resources and Conservation Commons

Moses, Wesley J.; Gitelson, Anatoly A.; Berdnikov, Sergey; and Povazhnyy, Vasiliy, "Satellite Estimation of Chlorophyll-a Concentration Using the Red and NIR Bands of MERIS-The Azov Sea Case Study" (2009). Papers in Natural Resources. 224.

https://digitalcommons.unl.edu/natrespapers/224

This Article is brought to you for free and open access by the Natural Resources, School of at DigitalCommons@University of Nebraska - Lincoln. It has been accepted for inclusion in Papers in Natural Resources by an authorized administrator of DigitalCommons@University of Nebraska - Lincoln. 


\title{
Satellite Estimation of Chlorophyll- $a$ Concentration Using the Red and NIR Bands of MERIS—The Azov Sea Case Study
}

\author{
Wesley J. Moses, Anatoly A. Gitelson, Sergey Berdnikov, and Vasiliy Povazhnyy
}

\begin{abstract}
We present here the results of calibrating and validating a three-band model and, its special case, a two-band model, which use MEdium Resolution Imaging Spectrometer (MERIS) reflectances in the red and near-infrared spectral regions for estimating chlorophyll- $a$ (chl- $a$ ) concentration in inland, estuarine, and coastal turbid productive waters. During four data collection campaigns in 2008 and one campaign in 2009 in the Taganrog Bay and the Azov Sea, Russia, water samples were collected, and concentrations of chl- $a$ and total suspended solids were measured in the laboratory. The data collected in 2008 were used for model calibration, and the data collected in 2009 were used for model validation. The models were applied to MERIS images acquired within two days from the date of in situ data collection. Two different atmospheric correction procedures were considered for processing the MERIS images. The results illustrate the high potential of the models to estimate chl- $a$ concentration in turbid productive (Case II) waters in real time from satellite data, which will be of immense value to scientists, natural resource managers, and decision makers involved in managing the inland and coastal aquatic ecosystems.
\end{abstract}

Index Terms-Chlorophyll- $a$ (chl- $a$ ), MEdium Resolution Imaging Spectrometer (MERIS), remote sensing, spectral algorithm, turbid productive waters.

\section{INTRODUCTION}

A S A HABITAT pool for a wide variety of flora and fauna, the inland, estuarine, and coastal waters serve as critical agents for sustaining biodiversity. They are also of great recreational value to humans. As such, it is essential that the biophysical conditions of these waters be regularly monitored so as to ensure that their ecological balance is maintained. Chlorophyll- $a$ (chl- $a$ ) concentration is used as a key indicator of the biophysical status of these water bodies. Estimating chl- $a$ concentration in real time is essential for the continuous monitoring of these waters. Nevertheless, no operational algorithm exists as yet for directly estimating chl- $a$ concentration from satellite data for such turbid productive

Manuscript received March 27, 2009; revised June 12, 2009. First published August 18, 2009; current version published October 14, 2009. This work was supported in part by the NASA Land Cover Land Use Change program under Grant NNG06GG17G to A.G. and in part by funds from the Hatch Act.

W. J. Moses and A. A. Gitelson are with the Center for Advanced Land Management Information Technologies, School of Natural Resources, University of Nebraska-Lincoln, Lincoln, NE 68583 USA (e-mail: wmoses@calmit.unl.edu; agitelso@unlnotes.unl.edu).

S. Berdnikov and V. Povazhnyy are with the Southern Scientific Center of the Russian Academy of Sciences, Rostov-on-Don 344 000, Russia (e-mail: berdnikov@mmbi.krinc.ru; povazhnyi@mmbi.krinc.ru).

Digital Object Identifier 10.1109/LGRS.2009.2026657 waters. This letter presents a definite and significant step toward calibrating and validating a spectral algorithm for estimating chl- $a$ concentrations in turbid productive inland, estuarine, and coastal waters using satellite data.

The turbid productive waters, where phytoplankton is not the sole dominator of the optical properties, are categorized as Case II waters [1]. Due to the optical complexities of the Case II waters, the blue-green algorithms routinely applied for estimating chl- $a$ concentration in open oceans fail when applied to turbid productive waters [2]-[4]. Recently, a threeband model and, its special case, a two-band model, which use reflectances in the red and near-infrared (NIR) spectral regions, were suggested for estimating chl- $a$ concentration in turbid productive waters [5]-[7]. These NIR-red models were formulated as follows:

The Three-Band Model :

$$
\text { chl- } a \propto\left(R_{\lambda_{1}}^{-1}-R_{\lambda_{2}}^{-1}\right) \times R_{\lambda_{3}}
$$

The Two-Band Model

$$
\text { chl- } a \propto\left(R_{\lambda_{1}}^{-1}\right) \times R_{\lambda_{3}} \text {. }
$$

Using reflectance data collected with field spectrometers, Dall'Olmo and Gitelson [6] and Gitelson et al. [8], [9] demonstrated that these models give accurate estimates of chl- $a$ concentration for turbid productive waters with a wide range of biophysical characteristics. It was also shown that the models yield high accuracies when the waveband locations and spectral widths are chosen to match the wavebands of MODerate Resolution Imaging Spectroradiometer (MODIS) and MEdium Resolution Imaging Spectrometer (MERIS).

In this letter, for the first time, we have calibrated and validated the NIR-red models using actual MERIS data, in contrast to the simulated reflectances from in situ data that were used in [6], [8], and [9]. For our purposes, MERIS provided a significant advantage over MODIS with its possession of a spectral band at $708 \mathrm{~nm}$ and its higher spatial resolution ( $260 \mathrm{~m} \times 290 \mathrm{~m}$ compared to $1 \mathrm{~km} \times 1 \mathrm{~km}$ for MODIS).

\section{Data AND Methods}

Five data collection campaigns were undertaken (in April, July, September, and October of 2008 and March of 2009) on the Taganrog Bay and the Azov Sea by the crew at the Southern Scientific Center of the Russian Academy of Sciences, Rostov-on-Don, Russia. Water samples were collected at 
each station, filtered through Whatman GF/F glass filters, and analyzed for chl- $a$ and total suspended solids (TSS). chl- $a$ was extracted in hot ethanol, and its concentration was quantified spectrophotometrically. TSS concentrations were determined gravimetrically.

MERIS images acquired up to two days before or after the date of in situ data acquisition were used in cases where sameday images were not available. The remote sensing reflectance was retrieved through two different procedures, namely, the Bright Pixel Atmospheric Correction and the Case 2 Regional Processing. The chief difference between the procedures lies in how the atmospheric effects on the image are corrected for. Detailed information about the atmospheric correction procedures can be found in [10], [11], [13], [14], and at http://envisat.esa.int/instruments/meris/atbd/.

\section{A. Bright Pixel Atmospheric Correction}

This is the standard atmospheric correction procedure routinely applied to MERIS images [10], [11]. In this procedure, the pixels are classified into Case I and Case II water pixels based on the radiance recorded by the sensor at $708 \mathrm{~nm}$. The Case I pixels have zero water-leaving radiance in the NIR region. For these pixels, the at-sensor radiance recorded at the NIR wavelengths is assumed to have come from atmospheric contribution, and these pixels are subjected to the conventional atmospheric correction procedure according to the method suggested by Gordon and Wang [12]. For the Case II pixels, the radiances recorded at the NIR wavebands are used in an iterative procedure to isolate the water-leaving radiance and thus factor out the aerosol scattering at these wavelengths. This estimated measure of aerosol scattering is then used in the same procedure as that of Gordon and Wang [12] to extrapolate the aerosol scattering at shorter wavelengths and retrieve the water-leaving radiance and, subsequently, the remote sensing reflectance at all wavelengths.

\section{B. Case 2 Regional Processing}

This method is a neural-network-based procedure developed specifically for inland and coastal Case II waters where even the Bright Pixel Atmospheric Correction procedure yields negative reflectances [13], [14]. The neural network was trained based on radiances simulated by radiative transfer solutions and built to parameterize the relationship between the topof-atmosphere radiances and the water-leaving radiances. The recorded radiances at 12 wavebands (at visible and NIR wavelengths) were used in the neural network to retrieve the water-leaving radiance and, subsequently, the remote sensing reflectance.

Model Calculation: After the retrieval of remote sensing reflectance from MERIS images, the three-band model was applied as

$$
\text { chl- } a \propto\left(R_{665}^{-1}-R_{708}^{-1}\right) \times R_{753}
$$

where $R_{x}$ is the remote sensing reflectance at the waveband centered at $x \mathrm{~nm}$. The corresponding MERIS waveband numbers are $7(665 \mathrm{~nm}), 9(708 \mathrm{~nm})$, and $10(753 \mathrm{~nm})$.

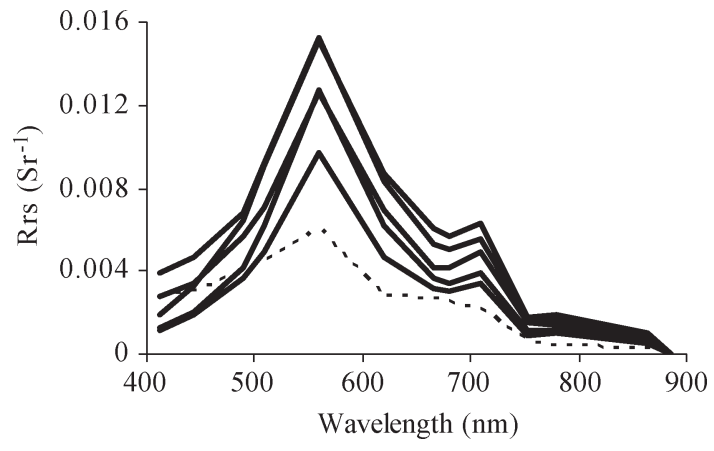

Fig. 1. Reflectance spectra from stations with chl- $a$ concentrations between 23 and $26 \mathrm{mg} \cdot \mathrm{m}^{-3}$. The spectrum shown as a dashed line has a distinct lack of spectral features in the red and NIR regions, in contrast to the rest of the spectra.

For the two-band model, $\lambda_{3}$ was chosen as $708 \mathrm{~nm}$ [7] instead of $753 \mathrm{~nm}$. The reflectance at $708 \mathrm{~nm}$ well represents the chlinduced reflectance peak in the NIR [7] while the reflectance at $753 \mathrm{~nm}$ does not as it mostly depends only on scattering by suspended particles. Moreover, the magnitude of the waterleaving radiance at $753 \mathrm{~nm}$ is much lower than that at $708 \mathrm{~nm}$ due to increased absorption by water at longer wavelengths. Thus, the uncertainties of the atmospheric correction procedure due to low signal-to-noise ratio are less amplified at $708 \mathrm{~nm}$ than at $753 \mathrm{~nm}$. Furthermore, with $708 \mathrm{~nm}$ being closer to $\lambda_{1}$ $(665 \mathrm{~nm})$, the atmospheric effect at $708 \mathrm{~nm}$ is closer to that at $665 \mathrm{~nm}$. This makes the two-band model with $\lambda_{3}$ at $708 \mathrm{~nm}$ less sensitive to spectrally nonuniform atmospheric effects. Thus the two-band model was applied as

$$
\text { chl- } a \propto\left(R_{665}^{-1}\right) \times R_{708} .
$$

\section{Results AND Discussion}

The chl- $a$ concentrations measured in situ were compared with the three-band and the two-band model values that were calculated using (3) and (4). Of all the stations where in situ data were collected, the stations that satisfied the following criteria were considered for the comparisons.

1) The station is at least at a two-pixel length from the shoreline.

2) The station is on a cloud/haze-free pixel in an image acquired within two days before/after the date of in situ data collection.

3) The atmospheric correction procedure did not produce reflectance spectra with negative values beyond $443 \mathrm{~nm}$.

4) The reflectance spectrum is not inconsistent in its spectral shape with the observed in situ data.

Outliers of the latter kind, which were very few, were identified by comparison with reflectance spectra from stations with similar chl- $a$ concentration (Fig. 1). The spectra in Fig. 1 correspond to stations with chl- $a$ concentrations between 23.3 and $26.5 \mathrm{mg} \cdot \mathrm{m}^{-3}$. In contrast to the solid-line spectra, the dashed-line spectrum at the bottom has a distinct lack of the typical chl- $a$ absorption in the red region $(665 \mathrm{~nm})$ and the peak reflectance in the NIR region $(708 \mathrm{~nm})$. Such outliers are deemed to have resulted from any one or a combination of the following factors: 1) within-pixel spatial heterogeneity 

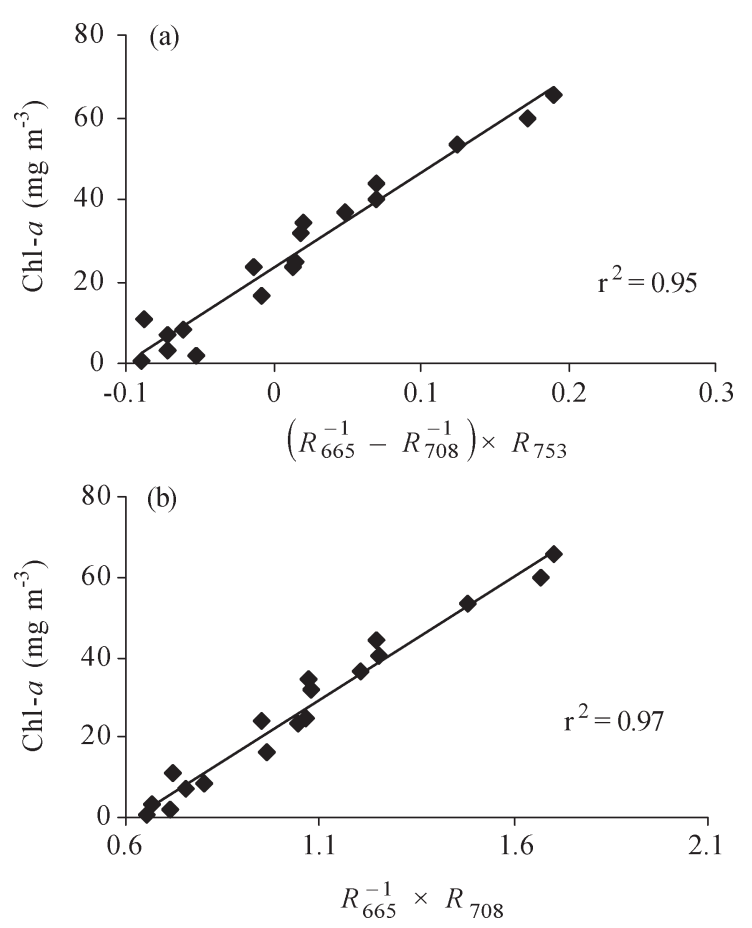

Fig. 2. Calibration of (a) the three-band and (b) the two-band models for the Bright Pixel Atmospheric Correction procedure.

of chl- $a$ distribution, resulting in the point in situ observation being not representative of the satellite pixel; 2) an actual biophysical change in the water body between the time of in situ data collection and time of the satellite image acquisition; and 3 ) erroneous retrieval of the remote sensing reflectance.

Altogether from the five in situ data collection campaigns, there were 18 stations from the 2008 data set and 8 stations from the 2009 data set that satisfied the aforementioned criteria. The stations from the 2008 data set were used to establish and calibrate the relationship between the chl- $a$ concentrations and the model values, and the stations from the 2009 data set were used to test the validity of the algorithms. The minimum, maximum, median, and mean in situ chl- $a$ concentrations of the 18 stations for calibration were $0.63,65.51,24.35$, and $26.97 \mathrm{mg} \cdot \mathrm{m}^{-3}$, respectively. The corresponding figures for the 8 stations for validation were $18.37,47.86,26.44$, and $28.56 \mathrm{mg} \cdot \mathrm{m}^{-3}$, respectively. The TSS concentration ranged from 0.4 to $27.4 \mathrm{~g} \cdot \mathrm{m}^{-3}$ for the entire data set.

\section{A. Bright Pixel Atmospheric Correction}

For the stations chosen for calibration, the three-band and the two-band model values had a very close linear relationship with in situ chl- $a$ concentrations, with a coefficient of determination $\left(r^{2}\right)$ higher than 0.95 (Fig. 2).

The calibrated NIR-red MERIS algorithms were given as follows:

The three-band MERIS algorithm:

$$
\text { chl- } a=232.29\left[\left(R_{665}^{-1}-R_{708}^{-1}\right) \times R_{753}\right]+23.174
$$

The two-band MERIS algorithm:

$$
\text { chl- } a=61.324\left[R_{665}^{-1} \times R_{708}\right]-37.94 \text {. }
$$
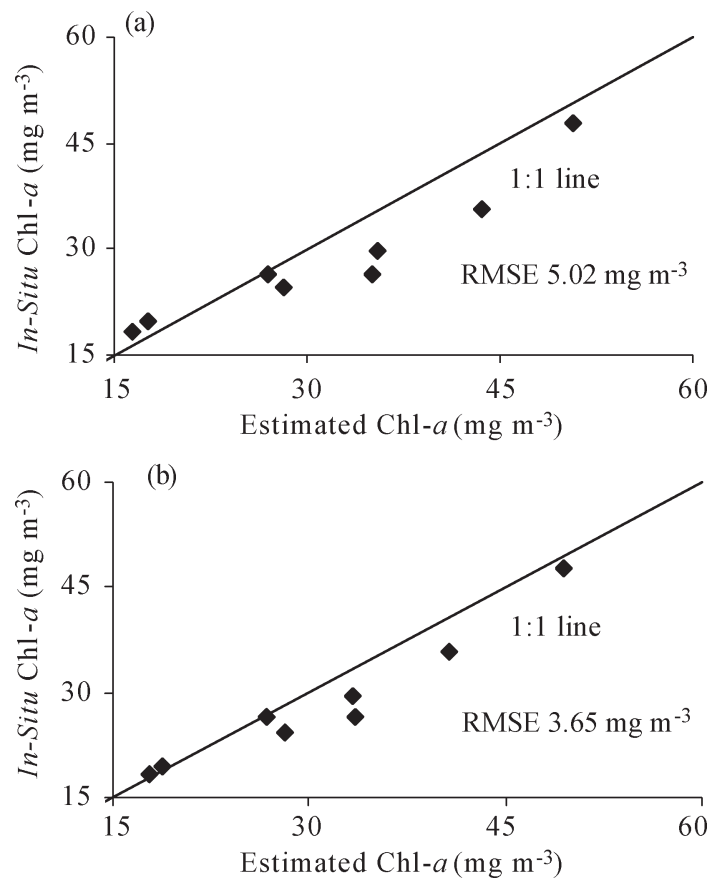

Fig. 3. Validation of the MERIS NIR-red algorithms: Relationships between the chl- $a$ concentrations measured in situ and estimated by (a) the three-band and (b) the two-band MERIS algorithms for the Bright Pixel Atmospheric Correction procedure.

The slope and intercept of both the MERIS algorithms compared well with the slope and intercept of the relationships derived from in situ reflectances collected in 2008 from several lakes in Nebraska, U.S. [9]. The slope and intercept of the three-band MERIS algorithm were 232.29 and $23.174 \mathrm{mg}$. $\mathrm{m}^{-3}$, respectively, whereas the corresponding figures for the in situ three-band algorithm were 216.22 and $22.21 \mathrm{mg} \cdot \mathrm{m}^{-3}$, respectively. Similarly, the slope and intercept of the two-band MERIS algorithm were 61.324 and $-37.94 \mathrm{mg} \cdot \mathrm{m}^{-3}$, respectively, whereas the corresponding figures for the in situ twoband algorithm were 63.44 and $-41.9 \mathrm{mg} \cdot \mathrm{m}^{-3}$, respectively. Further work needs to be done to test the stability of these parameters. The quality of atmospheric correction is bound to have an impact on the magnitude of these parameters. Dall'Olmo et al. [4] analyzed the propagation of systematic errors due to atmospheric correction in the NIR-red models and concluded that the models are reasonably resistant to such errors.

The algorithms thus calibrated were used to estimate the chl- $a$ concentration at the eight stations from the 2009 data set, which was marked for validation. The validation procedure included the following: 1) the estimation of chl- $a$ concentrations by applying the calibrated algorithms (5) and (6) to the remote sensing reflectances retrieved for the stations in the validation data set, and 2) the comparison between the estimated chl- $a$ concentrations and the in situ chl- $a$ concentrations. The comparison was remarkably close (Fig. 3). The threeband algorithm yielded a root-mean-square error (rmse) of $5.02 \mathrm{mg} \cdot \mathrm{m}^{-3}$ [Fig. 3(a)], while the two-band algorithm had an rmse of $3.65 \mathrm{mg} \cdot \mathrm{m}^{-3}$ [Fig. 3(b)].

When applied to data from field spectrometers [6], [8], [9], the three-band model had a higher accuracy than the two-band 

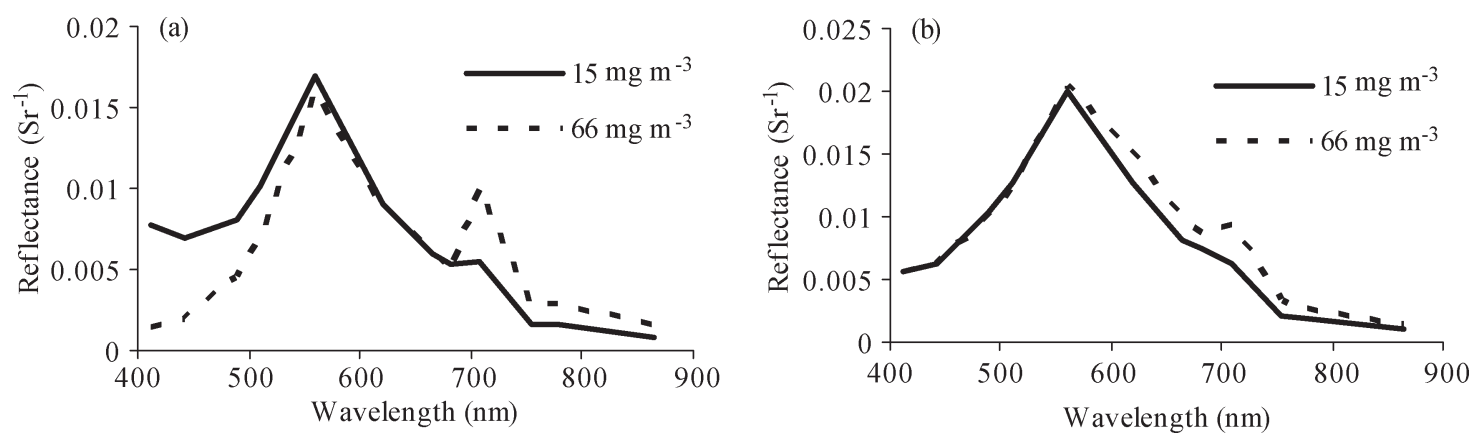

Fig. 4. Reflectance spectra of two stations retrieved using (a) the Bright Pixel Atmospheric Correction procedure and (b) the Case 2 Regional Processing: The spectral features in the red and NIR regions are better pronounced in proportion to the increase in chl- $a$ concentration in the reflectance spectra from the Bright Pixel Atmospheric Correction procedure than those from the Case 2 Regional Processing method.
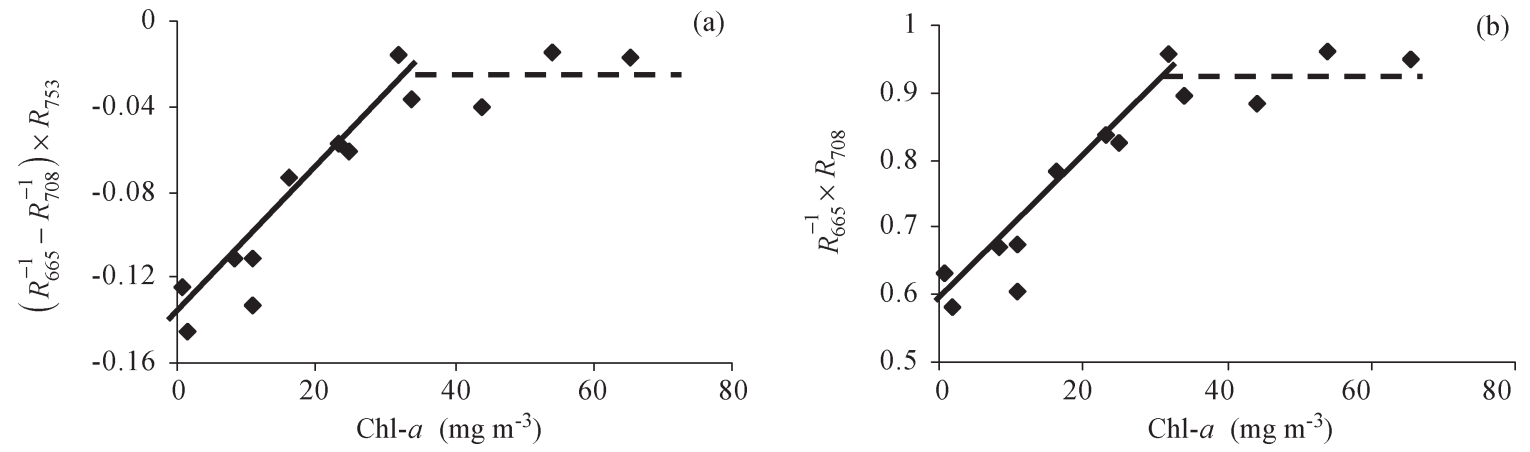

Fig. 5. In situ chl- $a$ concentrations versus (a) the three-band and (b) the two-band NIR-red MERIS model values for the Case 2 Regional Processing method.

model due to the effective removal of the effects of constituents other than chl- $a$ (e.g., nonalgal particles and colored dissolved organic matter) on the measured reflectance through the subtraction of the reciprocal reflectance at $\lambda_{2}$ in (1). The effects of the other constituents are magnified at lower concentrations of chl- $a$. In this letter, the $\lambda_{3}$ for the three-band model (3) was fixed at a longer wavelength $(750 \mathrm{~nm})$ than the $\lambda_{3}$ (at $708 \mathrm{~nm}$ ) for the two-band model (4). Thus, the three-band model was more sensitive than the two-band model to uncertainties in the atmospheric correction procedure due to the low signalto-noise ratio, particularly for stations with low magnitudes of reflectance in the NIR region. This may explain the looser fit of points with chl- $a$ concentration below $10 \mathrm{mg} \cdot \mathrm{m}^{-3}$ [Fig. 2(a)] and the slightly higher rmse for the three-band model.

The accuracies of both the NIR-red MERIS algorithms (5) and (6) were significantly better than what was obtained from the OC4v4 algorithm [15], [16]. For example, when the OC4v4 algorithm was applied to a MODIS image processed by the MUMM atmospheric correction procedure [17] for the March 2009 data set, the coefficient of determination of the relationship between the estimated and measured chl- $a$ concentrations was as low as 0.11 . Processing the MODIS data through the other available atmospheric correction procedures did not yield better results.

\section{B. Case 2 Regional Processing}

The three-band and the two-band model values derived from the Case 2 Regional Processing method did not have as close a relationship with in situ chl- $a$ concentrations as did the model values from the Bright Pixel Atmospheric Correction procedure. In this procedure, with increase in chl- $a$ concentration, the spectral reflectance features in the red and NIR regions (specifically, the reflectance peak around $700 \mathrm{~nm}$ [7]) were not proportionally increasingly pronounced as much as they should be (see in situ reflectance spectra in Fig. 2, [6]) and as they were in the reflectance spectra from the Bright Pixel Atmospheric Correction procedure (Fig. 4). Thus, for both models, the relationships between the in situ chl- $a$ concentrations and the model values were not uniform for the whole range of chl- $a$ concentrations. The relationships were quite close for chl- $a$ below $35 \mathrm{mg} \cdot \mathrm{m}^{-3}$, with the coefficient of determination as high as 0.9 for both the models. However, the relationships broke, and the models lost their sensitivity to chl- $a$ above $35 \mathrm{mg} \cdot \mathrm{m}^{-3}$ (Fig. 5).

The neural-network procedure is applied as a two-step process: 1) the retrieval of water-leaving radiances from the atsensor radiances (atmospheric correction) and 2) the inversion of the water-leaving radiances for the retrieval of the concentrations of the constituents in water. Both these steps have to be independently investigated to identify the reason for the apparent suppression of the spectral features in the red and NIR regions, which renders the procedure as yet unreliable for estimating chl- $a$ concentrations over a wide range.

\section{CONCLUSION}

The results presented here illustrate the high potential of the three-band and the two-band NIR-red models to accurately estimate the chl- $a$ concentration in turbid productive waters using MERIS data. It has already been shown that the 708-nm MERIS 
band can be used for the detection of phytoplankton bloom [18]. However, to the best of our knowledge, this is the first time that the NIR-red models have been successfully calibrated and validated to quantitatively estimate chl- $a$ concentration using satellite data.

Nevertheless, challenges still remain in calibrating the models for their universal application to satellite data. The models need to be calibrated and validated with a larger data set. This necessitates the adaptation of in situ data collection technique to maximize the number of stations that can be assessed with a single satellite image. The spatial heterogeneity of the water within a satellite pixel area around each station needs to be accounted for, so are any changes in the biophysical and biooptical characteristics of the water at each station during the time elapsed between the satellite overpass and the in situ data collection. Accurate and reliable atmospheric correction of the satellite data is still a major challenge for turbid productive waters. Provided that these factors can be effectively accounted for, robustly calibrated algorithms can be developed for applying the NIR-red models to satellite data for realtime quantitative measures of chl- $a$ concentration, which will greatly benefit scientists and natural resource managers in making informed decisions on managing the inland, coastal, and estuarine ecosystems.

\section{ACKNOWLEDGMENT}

The authors would like to thank the ESA Earth Observation Missions Helpdesk Team for providing the MERIS data and the University of Nebraska Agricultural Research Division, Lincoln, for providing their resources.

\section{REFERENCES}

[1] A. Morel and L. Prieur, "Analysis of variations in ocean color," Limnol. Oceanogr., vol. 22, no. 4, pp. 709-722, Jul. 1977.

[2] K. Carder, F. Chen, J. Cannizzaro, J. Campbell, and B. Mitchell, "Performance of the MODIS semi-analytical ocean color algorithm for chlorophyll-a," Adv. Space Res., vol. 33, no. 7, pp. 1152-1159, Jan. 2004.

[3] M. Darecki and D. Stramski, "An evaluation of MODIS and SeaWiFS bio-optical algorithms in the Baltic Sea," Remote Sens. Environ., vol. 89, no. 3, pp. 326-350, Feb. 2004.

[4] G. Dall'Olmo, A. Gitelson, D. Rundquist, B. Leavitt, T. Barrow, and J. Holz, "Assessing the potential of SeaWiFS and MODIS for estimating chlorophyll concentration in turbid productive waters using red and near- infrared bands," Remote Sens. Environ., vol. 96, no. 2, pp. 176-187, May 2005.

[5] G. Dall'Olmo, A. Gitelson, and D. Rundquist, "Towards a unified approach for remote estimation of chlorophyll-a in both terrestrial vegetation and turbid productive waters," Geophys. Res. Lett., vol. 30, no. 18, pp. HLS1.1-HLS1.4, Mar. 2003.

[6] G. Dall'Olmo and A. Gitelson, "Effect of bio-optical parameter variability on the remote estimation of chlorophyll-a concentration in turbid productive waters: Experimental results," Appl. Opt., vol. 44, no. 3, pp. 412-422, Jan. 2005.

[7] A. Gitelson, "The peak near $700 \mathrm{~nm}$ on radiance spectra of algae and water-Relationships of its magnitude and position with chlorophyll concentration," Int. J. Remote Sens., vol. 13, no. 17, pp. 3367-3373, Nov. 1992.

[8] A. Gitelson, G. Dall'Olmo, W. Moses, D. Rundquist, T. Barrow, T. Fisher, D. Gurlin, and J. Holz, "A simple semi-analytical model for remote estimation of chlorophyll-a in turbid waters: Validation," Remote Sens. Environ., vol. 112, no. 9, pp. 3582-3593, Sep. 2008.

[9] A. Gitelson, D. Gurlin, W. Moses, and T. Barrow, "A bio-optical algorithm for the remote estimation of the chlorophyll-a concentration in case 2 waters," Environ. Res. Lett., 2009, to be published.

[10] G. Moore, J. Aiken, and J. Lavender, "The atmospheric correction of water colour and the quantitative retrieval of suspended particulate matter in case II waters: Application to MERIS," Int. J. Remote Sens., vol. 20, no. 9, pp. 1713-1733, Jun. 1999.

[11] J. Aiken and G. Moore, "ATBD case $2 \mathrm{~s}$ bright pixel atmospheric correction," Center Coastal Marine Sci., Plymouth Marine Lab., Plymouth, U.K., Rep. PO-TN-MEL-GS-0005, Feb. 2000, vol. 4.

[12] H. Gordon and M. Wang, "Retrieval of water-leaving radiance and aerosol optical-thickness over the oceans with SeaWiFS-A preliminary algorithm," Appl. Opt., vol. 33, no. 3, pp. 443-452, Jan. 1994.

[13] R. Doerffer and H. Schiller, "The MERIS case 2 water algorithm," Int. J. Remote Sens., vol. 28, no. 3/4, pp. 517-535, Jan. 2007.

[14] R. Doerffer and H. Schiller, "MERIS regional coastal and lake case 2 water project atmospheric correction ATBD," Inst. Coastal Res., GKSS Res. Center, Geesthacht, Germany, Rep. GKSS-KOF-MERIS-ATBD01, Jun. 2008, vol. 1.

[15] J. O'Reilly, S. Maritorena, B. Mitchell, D. Siegel, K. Carder, S. Garver, M. Kahru, and C. McClain, "Ocean color chlorophyll algorithms for SeaWiFS," J. Geophys. Res., vol. 103, no. C11, pp. 24937-24 953, Oct. 1998.

[16] J. O'Reilly, S. Maritorena, M. C. O'Brien, D. A. Siegel, D. Toole, D. Menzies, R. C. Smith, J. L. Mueller, B. G. Mitchell, M. Kahru, F. P. Chavez, P. G. Strutton, G. F. Cota, S. B. Hooker, C. R. McClain, K. L. Carder, F. Muller-Karger, L. Harding, A. Magnuson, D. Phinney, G. F. Moore, J. Aiken, K. R. Arrigo, R. M. Letelier, and M. Culver, "SeaWiFS postlaunch calibration and validation analyses, Part 3," NASA Goddard Space Flight Center, Greenbelt, MD, NASA Tech. Memo. 2000206892, 2000, vol. 11 .

[17] K. Ruddick, F. Ovidio, and M. Rijkeboer, "Atmospheric correction of SeaWiFS imagery for turbid coastal and inland waters," Appl. Opt., vol. 39, no. 6, pp. 897-912, Feb. 2000.

[18] J. Gower, S. King, G. Borstad, and L. Brown, "Detection of intense plankton blooms using the $709 \mathrm{~nm}$ band of the MERIS imaging spectrometer," Int. J. Remote Sens., vol. 26, no. 9, pp. 2005-2012, May 2005. 